\title{
Relationship of psychophysiological characteristics with different levels of motivation in judo athletes of high qualification
}

\author{
Korobeynikov G.V. ${ }^{1}$, Korobeynikova L.G. ${ }^{1}$, Romanyuk L.V. ${ }^{2}$, Dakal N.A. ${ }^{3}$, Danko G.V. ${ }^{1}$ \\ ${ }^{1}$ National University of Physical Education and Sport of Ukraine, Ukraine \\ ${ }^{2}$ Lviv State University of Internal Affairs, Ukraine \\ ${ }^{3}$ National technical university of Ukraine "Igor Sikorsky Kyiv Polytechnic Institute”, Ukraine
}

\begin{abstract}
Purpose:

to study the connection of psychophysiological characteristics with different levels of motivation in judo athletes of high qualification.

Material: $\quad$ highly qualified athletes were examined, members of the National Judo Team (men). All athletes ( $\mathrm{n}=$ 25) were divided into three groups, depending on the level of motivation to achieve success.

Results: it is established that the high level of motivation for achieving success in judo is provided by activation of neurodynamic, cognitive functions and the level of light resistance. Athletes with a high level of motivation to achieve success is observed the predominance of the values of neurodynamic functions: endurance of the nervous system; speed of visual reactions. Athletes with an average level of motivation to achieve success identified higher values: productivity, speed, accuracy, effectiveness of verbal information. Athletes with a predominance of avoidance of failure motivation have a preference for other groups in the speed, efficiency and stability of the processes of thinking and processing information.

Conclusions: judo athletes with a predominance of motivation to avoid a failure form coping strategy to prevent psycho-emotional stress. This helps to minimize the exhaustion of vegetative resources in conditions of extreme sports activity. Judo athletes with high level of motivation to achieve success, the presence of mental state of relative comfort is associated with the search for support among others and orientation toward internal beliefs.

Keywords: $\quad$ psychophysiological, achievement motivation, judo athletes, neurodynamic, cognitive.
\end{abstract}

\section{Introduction}

Numerous studies indicate the presence of external factors affecting the effectiveness of sports activities in extreme conditions. These allowed determining basic, psychophysiological and neurodynamic properties of the athlete. These include individual psycho-physiological features and criteria for professional fitness, which determine differentiated approach to selection and orientation in sports $[1,2]$. Such are the properties of higher nervous activity: strength, mobility and balance of nervous processes. Psychophysiological characteristics (as derivatives of the properties of higher nervous activity) are generally considered to be the basis of human abilities and components of the individual style of activity [3]. In the judgment of Teplov B.M., only a combination of different abilities characterize this person [4].

The properties of the nervous system are manifested not so much in productive as in the procedural characteristics of activity. The procedural characteristics of the activity are largely determined by the individualtypological properties of the individual [5].

Merlin V.S. was developed the theory of integral individuality. The connections between the multilevel properties of individuality vary depending on what actions, operations and intermediate goals the person chooses to accomplish the tasks. Stable individual systems of goals, actions and operations in the objective activity (c) Korobeynikov G.V., Korobeynikova L.G., Romanyuk L.V.,

Dakal N.A., Danko G.V., 2017

doi:10.15561/18189172.2017.0603 are designated as an individual style of human activity [6]. The style of activity is formed depending on the role of various factors: turn for work in different modes; the ratio of general and special abilities; typological properties; anthropometric data; morphological features [7]. However, the formation of individual strategies in sports occurs against the background of the corresponding achievement motivation [8].

Achievement motivation is one of the most essential properties of personality [9]. The question of the relationship of individual psychological characteristics with the processes of motivation has a particular importance [10]. The motive of achievement is one of the leading motives of the subject of sports activity. The motif is ambiguously associated with individual typological characteristics. The motive of achievement forms statistically significant positive relationship with the indicators: orientation to a certain activity; adaptability to external conditions; combinatorial thinking; spatial imagination. Motive of achievement forms statistically significant negative correlation with the indicators of: anxiety, emotional instability [11].

Just under the testing of the motor abilities it is impossible to obtain complete information about the athlete's readiness for the competition. In competitive conditions, the physical qualities and sides of preparedness are not manifested in isolation, but in a complex relationship [12].

The motivation of achievement, in modern combats, 
is important for psychological and tactical training [13]. In the conditions of competitive activity the realization of the motivational program largely depends on the athlete's ability to adequate perception and organization of external information [14].

The aim of the work is to study the connection of psychophysiological characteristics with different levels of motivation for attaining high qualification in judo athletes.

\section{Materials and methods}

Participants. Highly qualified athletes, members of the National Judo Team (men) were examined. All athletes $(\mathrm{n}=25)$ were divided into three groups, depending on the level of motivation to achieve success (according to Mehrabian A. [15]). The first group is athletes with a high level of motivation to achieve success $(n=9)$. The second group is athletes with an average and above average levels of motivation to achieve success $(n=10)$. The third group is athletes with low and below average levels of motivation to achieve success $(\mathrm{n}=6)$.

The design of the research.

The motivation for achievement was based on a questionnaire test (Mehrabian A. [15]), adapted by Shapkin S.A. [16]. The test is intended to diagnose two generalized motives of the individual - the motive for success and the motive for avoiding failure. At the same time, the prevalence of one or another motive is evaluated. The test is built on the basis of the theory of achievement motivation by J. Atkinson. The test is a questionnaire, the design of which uses factor analysis. Factor analysis has two forms - male and female. The male form includes 32 points, the female -30 . The degree of agreement with the statement can range from a complete denial to full acceptance. High test scores indicate a predominance of motivation for success. Low test scores indicate a predominance of avoidance of failure.

Neurodynamic, psychomotor and cognitive characteristics of judo athletes were examined for study the connection of psychophysiological characteristics with different levels of motivation $[3,5]$.

Neurodynamic and psychomotor characteristics have been studied with the help of the following techniques: tapping test (endurance of the nervous system), reaction to a moving object (balance of nervous processes), functional mobility of nervous processes and time of a simple sensorimotor reaction.

The study of cognitive functions included: evaluation of perceptual velocity, methods of comparing numbers, memory for words and establishing patterns.

Statistical analysis. Processing of findings was carried out with the help of computer packages of applied programs "Statistica 6.0". It is established that the studied indicators are not amenable to the law of normal distribution. Therefore, to determine the statistical differences between the samples, the criterion for signed Wilcoxon rank sums was used. To demonstrate the distribution of data were used the interquartile range, the first $(25 \%)$ and the third $(75 \%)$ quartiles.

\section{Results}

Table 1 presents the average values of neurodynamic and psychomotor indicators.

Analysis of the results of the tapping test shows that there are significant differences between the first and second groups of athletes in terms of endurance, stability and porosity. At the same time, the indices of endurance and stability are significantly higher in judo athletes of the second group. The values of the duty cycle are significantly higher in athletes of the first group (Table 1).

Under the comparison of the values of the first and third groups of athletes in terms of the level of achievement motivation, significant differences in indices of endurance, frequency of contact and stability were established (Table 1). In this case, the values of the endurance index are higher for athletes of the first group. The values of the frequency of touch and stability are higher for athletes of the third group (Table 1).

The stability index in the conditions of tapping test is characterized by the level of variability (coefficient of variation). The smaller the coefficient of variation, the higher the stability index of taping test.

The features of cognitive functions in judo have been studied with the help of the technique "Perceptual speed", "Comparison of numbers", "Memory for words" and "Establishment of regularities".

Table 2 represents the average values of cognitive functions in athletes with different levels of motivation to achieve success.

The analysis of the parameters of the method "Perceptual speed" indicates a significant difference in accuracy between athletes of all three groups. Higher level of values is observed in athletes of the second group - with an average and above average levels of motivation to achieve success.

According to the efficiency index - significantly high values for judo athletes of the second group were determined. In terms of productivity and speed, there are no significant differences (Table 2).

The values of the indicators of the method "Comparison of numbers" indicate the presence of significant differences between the first and second groups of athletes in all respects: efficiency, latency of reaction, accuracy and stability. At the same time, higher level of values for all these indicators is determined by athletes in the second group - athletes with an average and above average levels of motivation to achieve success. This indicates higher level of development in athletes of this group: operative visual memory and counting intelligence; high speed of analysis and processing of information when making decisions; stability of performing actions; higher level of concentration and stability of attention (Table 2).

There are also significant differences between the first and third groups of athletes in terms of performance such as: effectiveness, reaction latency and stability. Moreover, higher level of values of these indicators is determined in judo athletes of the third group - athletes with low and below average levels of motivation to achieve success (Table 2). 
Table 1. Neurodynamic and psychomotor characteristics of high qualification judo athletes with different levels of motivation (median, lower quartile, upper quartile)

\begin{tabular}{|c|c|c|c|}
\hline Indicators & $\begin{array}{l}\text { High level of motivation } \\
\text { to achieve a success, first } \\
\text { group }(n=9)\end{array}$ & $\begin{array}{l}\text { Average level of } \\
\text { motivation to achieve a } \\
\text { success, second group } \\
(n=10)\end{array}$ & $\begin{array}{l}\text { Motivation to avoid a } \\
\text { failure, third group }(n=6)\end{array}$ \\
\hline \multicolumn{4}{|l|}{ Tapping test } \\
\hline Tolerance, standard unit & $\begin{array}{l}(-1,47) ; \\
(-1,68) ;(-0,24)\end{array}$ & $\begin{array}{l}(-1,27)^{*} ; \\
(-2,33) ;(-1,23)\end{array}$ & $\begin{array}{l}(-1,63) * * * \\
(-2,21) ;(-1,23)\end{array}$ \\
\hline Touch frequency, quantity & $\begin{array}{l}5,98 \\
5,50 ; 6,21\end{array}$ & $\begin{array}{l}5,94 ; \\
5,50 ; 6,05\end{array}$ & $\begin{array}{l}6,03 \\
5,48 ; 6,63\end{array}$ \\
\hline Stability, \% & $\begin{array}{l}13,20 ; \\
9,04 ; 16,21\end{array}$ & $\begin{array}{l}8,96 * ; \\
7,67 ; 14,48\end{array}$ & $\begin{array}{l}9,93 * * * \\
8,85 ; 10,16\end{array}$ \\
\hline $\begin{array}{l}\text { Off-duty factor, standard } \\
\text { unit }\end{array}$ & $\begin{array}{l}3,32 ; \\
3,00 ; 3,81\end{array}$ & $\begin{array}{l}3,66 * ; \\
3,29 ; 4,49\end{array}$ & $\begin{array}{l}3,88 * * \\
3,05 ; 4,08\end{array}$ \\
\hline \multicolumn{4}{|l|}{ Balance of nervous process } \\
\hline Accuracy, standard unit & $\begin{array}{l}2,83 ; \\
2,67 ; 3,22\end{array}$ & $\begin{array}{l}2,73 * \\
2,45 ; 3,12\end{array}$ & $\begin{array}{l}2,62 * * * \\
1,89 ; 3,15\end{array}$ \\
\hline Stability, standard unit & $\begin{array}{l}3,70 \\
2,91 ; 4,10\end{array}$ & $\begin{array}{l}3,30 \\
3,22 ; 4,30\end{array}$ & $\begin{array}{l}3,35 * * * \\
2,69 ; 3,83\end{array}$ \\
\hline Excitation, standard unit & $\begin{array}{l}(-0,82) \\
(-1,78) ;(-0,22)\end{array}$ & $\begin{array}{l}(-0,54)^{*} ; \\
(-1,28) ;(-0,01)\end{array}$ & $\begin{array}{l}0,09 ; \\
(-1,09) ; 0,69\end{array}$ \\
\hline \multicolumn{4}{|c|}{ Functional mobility of nervous processes (FMNP) } \\
\hline Dynamism, standard unit & $\begin{array}{l}70,40 \\
60,57 ; 79,12\end{array}$ & $\begin{array}{l}70,00 ; \\
66,00 ; 75,85\end{array}$ & $\begin{array}{l}82,52 ; * * * \\
74,72 ; 85,47\end{array}$ \\
\hline Capacity, standard unit & $\begin{array}{l}1,76 ; \\
1,64 ; 1,84\end{array}$ & $\begin{array}{l}1,81 * ; \\
1,57 ; 1,92\end{array}$ & $\begin{array}{l}1,88 ; * * * \\
1,77 ; 2,00\end{array}$ \\
\hline $\begin{array}{l}\text { Full speed of information } \\
\text { organization, ms }\end{array}$ & $\begin{array}{l}380,00 ; \\
350,00 ; 410,00\end{array}$ & $\begin{array}{l}350,00 ; \\
320,00 ; 410,00\end{array}$ & $\begin{array}{l}350,00 ; \\
290,00 ; 380,00\end{array}$ \\
\hline Impulsion, standard unit & $\begin{array}{l}(-0,06) \\
(-0,13) ; 0,07\end{array}$ & $\begin{array}{l}(-0,01) \\
(-0,19) ; 0,09\end{array}$ & $\begin{array}{l}0,01 \\
(-0,02) ; 0,18\end{array}$ \\
\hline \multicolumn{4}{|c|}{ Sensomotor reaction (SMR) } \\
\hline $\begin{array}{l}\text { Latency period of } \\
\text { reaction, ms }\end{array}$ & $\begin{array}{l}260,00 \\
258,67 ; 274,77\end{array}$ & $\begin{array}{l}281,60 * ; \\
248,40 ; 316,03\end{array}$ & $\begin{array}{l}263,28 * * * ; \\
253,00 ; 270,77\end{array}$ \\
\hline Stability, \% & $\begin{array}{l}16,76 ; \\
13,70 ; 22,11\end{array}$ & $\begin{array}{l}13,46 ; \\
10,71 ; 16,06\end{array}$ & $\begin{array}{l}17,39 ; \\
12,08 ; 21,13\end{array}$ \\
\hline
\end{tabular}

Notes: * ${ }^{*} p<0.05$, in comparison with athletes with a high level of motivation to achieve success; ** $-p<0.05$, in comparison with athletes with an average and above average levels of motivation to achieve success.

A significantly high level of efficacy and latency of the reaction was revealed in athletes of the third group (Table 2). The lower values of the latency index of the reaction in judo athletes of the third group testify to the high speed of analysis and processing of information when making a decision.

The average values of the indicators of the method "Memory for words" indicate the presence of significant differences only in terms of the speed between the judo athletes of the second and third groups. Moreover, higher values in the third group of judo athletes are athletes with low and below average levels of motivation to achieve success. This determines in athletes of this group higher level of visual short-term memory for verbal information (Table 2).

Analysis of the values of the indicators of the method
"Establishment of regularities" indicates the presence of significant differences in performance and speed between the first and second groups of athletes. Above the level of values in the second group - athletes with an average and above average levels of motivation to achieve success (Table 2). This indicates higher level: ingenuity; ability to perceive and re-encode information; attention and memory; speed formation of skills and skills required for non-standard ways of processing information. Also, reliable differences in terms of productivity, accuracy and efficiency were determined. Higher level of values is observed in athletes of the first group. According to the speed indicator, there is a tendency to the reliability of differences between the athletes of the first and third groups. According to the efficiency index, there is a tendency to the reliability of the differences between the 
Table 2. Cognitive functions of high qualification judo athletes with different levels of motivation (median, lower quartile, upper quartile)

\begin{tabular}{|c|c|c|c|}
\hline Indicators & $\begin{array}{l}\text { High level of motivation } \\
\text { to achieve a success, first } \\
\text { group }(n=9)\end{array}$ & $\begin{array}{l}\text { Average level of } \\
\text { motivation to achieve a } \\
\text { success, second group } \\
(n=10)\end{array}$ & $\begin{array}{l}\text { Motivation to avoid a } \\
\text { failure, third group }(n=6)\end{array}$ \\
\hline \multicolumn{4}{|l|}{ Perceptual speed } \\
\hline Productivity, standard unit & $\begin{array}{l}58,00 ; \\
51,00 ; 72,00\end{array}$ & $\begin{array}{l}60,50 ; \\
51,00 ; 71,00\end{array}$ & $\begin{array}{l}68,00 ; \\
54,00 ; 73,00\end{array}$ \\
\hline Speed, standard unit & $\begin{array}{l}17,00 ; \\
14,24 ; 19,25\end{array}$ & $\begin{array}{l}16,13 ; \\
13,50 ; 18,75\end{array}$ & $\begin{array}{l}18,50 ; \\
16,50 ; 19,25\end{array}$ \\
\hline Accuracy, standard unit & $\begin{array}{l}0,93 ; \\
0,90 ; 0,99\end{array}$ & $\begin{array}{l}0,97^{*} ; \\
0,90 ; 0,98\end{array}$ & $\begin{array}{l}0,93 * * \\
0,70 ; 0,97\end{array}$ \\
\hline Effectiveness, standard unit & $\begin{array}{l}40,03 ; \\
38,86 ; 54,74\end{array}$ & $\begin{array}{l}46,00 * \\
41,41 ; 57,24\end{array}$ & $\begin{array}{l}54,00 ; \\
27,08 ; 60,83\end{array}$ \\
\hline \multicolumn{4}{|l|}{ Congruence of numbers } \\
\hline Effectiveness, standard unit & $\begin{array}{l}\text { 1457,65; } \\
976,55 ; 1709,10\end{array}$ & $\begin{array}{l}959,27 * ; \\
917,93 ; 1125,80\end{array}$ & $\begin{array}{l}836,72 * * * ; \\
811,03 ; 875,83\end{array}$ \\
\hline Latency period of reaction, $\mathrm{ms}$ & $\begin{array}{l}\text { 1365,60; } \\
953,11 ; 1634,15\end{array}$ & $\begin{array}{l}919,78 * ; \\
886,24 ; 1081,80\end{array}$ & $\begin{array}{l}836,71 * * * ; \\
792,02 ; 865,97\end{array}$ \\
\hline Accuracy, standard unit & $\begin{array}{l}0,96 ; \\
0,92 ; 0,97\end{array}$ & $\begin{array}{l}0,96 * ; \\
0,95 ; 0,98\end{array}$ & $\begin{array}{l}0,97 ; \\
0,95 ; 0,98\end{array}$ \\
\hline Stability, \% & $\begin{array}{l}34,14 ; \\
27,32 ; 40,30\end{array}$ & $\begin{array}{l}26,07 * \\
22,47 ; 29,72\end{array}$ & $\begin{array}{l}21,71 * ; \\
20,90 ; 24,09\end{array}$ \\
\hline \multicolumn{4}{|l|}{ Memory for words } \\
\hline Productivity, standard unit & $\begin{array}{l}19,00 ; \\
17,00 ; 21,00\end{array}$ & $\begin{array}{l}20,50 ; \\
18,00 ; 22,00\end{array}$ & $\begin{array}{l}21,00 ; \\
19,00 ; 26,00\end{array}$ \\
\hline Speed, standard unit & $\begin{array}{l}10,90 ; \\
6,50 ; 12,48\end{array}$ & $\begin{array}{l}9,55 ; \\
8,78 ; 12,20\end{array}$ & $\begin{array}{l}15,71 * * ; \\
11,08 ; 17,23\end{array}$ \\
\hline Accuracy, standard unit & $\begin{array}{l}0,65 ; \\
0,60 ; 0,70\end{array}$ & $\begin{array}{l}0,70 ; \\
0,60 ; 0,73\end{array}$ & $\begin{array}{l}0,70 ; \\
0,63 ; 0,87\end{array}$ \\
\hline Effectiveness, standard unit & $\begin{array}{l}34,31 ; \\
30,00 ; 43,75\end{array}$ & $\begin{array}{l}42,28 ; \\
30,00 ; 48,89\end{array}$ & $\begin{array}{l}43,89 ; \\
34,31 ; 72,22\end{array}$ \\
\hline \multicolumn{4}{|l|}{ Establishment of regularities } \\
\hline Productivity, standard unit & $\begin{array}{l}\text { 19,00; } \\
17,00 ; 23,00\end{array}$ & $\begin{array}{l}20,50 * ; \\
15,00 ; 22,00\end{array}$ & $\begin{array}{l}19,00 * * * ; \\
18,00 ; 22,00\end{array}$ \\
\hline Speed, standard unit & $\begin{array}{l}3,83 ; \\
3,40 ; 4,79\end{array}$ & $\begin{array}{l}4,66^{*} ; \\
3,50 ; 5,09\end{array}$ & $\begin{array}{l}4,48 ; * * * \\
4,31 ; 6,46\end{array}$ \\
\hline Accuracy, m & $\begin{array}{l}0,92 ; \\
0,80 ; 0,98\end{array}$ & $\begin{array}{l}0,89 ; \\
0,60 ; 0,95\end{array}$ & $\begin{array}{l}0,84 * * * \\
0,72 ; 0,88\end{array}$ \\
\hline Effectiveness, standard unit & $\begin{array}{l}76,00 ; \\
50,66 ; 82,80\end{array}$ & $\begin{array}{l}71,00 т ; \\
30,00 ; 82,80\end{array}$ & $\begin{array}{l}61,50 * * * ; \\
46,80 ; 74,80\end{array}$ \\
\hline
\end{tabular}

Notes: * ${ }^{*}$ p $<0.05$, in comparison with athletes with a high level of motivation to achieve success; $* *-p<0.05$, in comparison with athletes with an average and above average levels of motivation to achieve success.

first and second groups.

Features of the mental state of athletes were assessed using the methods "Stress Test" and the "Luscher color test".

The average values of the indicators according to these methods are presented in Table 3.

The average values of the indicators of the "Luscher color test" showed that significant differences were noted between the first and second groups in terms of performance: fatigue, deviation from autogenous norm, heteronomy and autonomy. There is a tendency to reliability of differences in the indicators of anxiety and eccentricity.

Also, reliable differences between the first and third groups were determined for the indicators: concentricity and heteronomy. Reliable differences between the second and third groups in terms of the deviations from the autogenous norm and concentricity were determined (Table 3).

The values of the fatigue index in the first group of 
athletes are lower than in the second group. This is the best indicator. The remaining indicators show an average level.

The analysis of the indicators of the "Stress test" testifies to significant differences in the stress-resistance index between the first and third groups. Higher rates are observed in the first group, with a high level of motivation to achieve success. In terms of throughput, there are higher rates: between the first and third group; between the second and third group. Higher rates are observed in athletes of the third group - judo athletes with low and below average levels of motivation to achieve success (Table 3).

In judo athletes of the first group (performance of strenuous activity) the obtained data testify to: higher resistance to the action of aversive (irritating) stimuli; high ability to maintain the maximum level of efficiency. Athletes of the third group (performing combined monitoring and discrete control actions) determine: higher level of distribution of visual attention between dynamic objects; higher processing speed of continuously incoming non-verbal information; higher level of coordination of movements (Table 3).

By the index of impulsivity, reliable differences between the first and second groups are determined. The lower rates were revealed in the athletes of the first group - athletes with a high level of motivation to achieve success (Table 3).

\section{Discussion}

Thus, a high level of motivation to achieve success in athletes is provided by the activation of neurodynamic, cognitive functions and the level of light resistance. In athletes with high level of motivation to achieve success, the values of neurodynamic functions predominate: endurance of the nervous system and speed of visual reactions. This circumstance as a whole reflects the general trend in the formation of motivation in combats $[3,17]$.

At athletes with an average level of motivation to

Table 3. The mental state of high qualification judo athletes with different levels of motivation (median, lower quartile, upper quartile)

\begin{tabular}{|c|c|c|c|}
\hline Indicators & $\begin{array}{l}\text { High level of motivation } \\
\text { to achieve a success, } \\
\text { first group ( } n=9)\end{array}$ & $\begin{array}{l}\text { Average level of } \\
\text { motivation to achieve a } \\
\text { success, second group } \\
(n=10)\end{array}$ & $\begin{array}{l}\text { Motivation to avoid } \\
\text { a failure, third group } \\
(n=6)\end{array}$ \\
\hline \multicolumn{4}{|l|}{ Luscher color test (LCT) } \\
\hline Efficiency, standard unit & $\begin{array}{l}\text { 12,00; } \\
11,00 ; 12,00\end{array}$ & $\begin{array}{l}8,00 * ; \\
7,00 ; 11,00\end{array}$ & $\begin{array}{l}\text { 11,00; } \\
10,00 ; 12,00\end{array}$ \\
\hline Tiredness, standard unit & $\begin{array}{l}2,00 ; \\
1,00 ; 2,00\end{array}$ & $\begin{array}{l}3,00 * ; \\
1,00 ; 4,00\end{array}$ & $\begin{array}{l}3,00 ; \\
0,00 ; 5,00\end{array}$ \\
\hline Anxiety, standard unit & $\begin{array}{l}0,00 ; \\
0,00 ; 1,00\end{array}$ & $\begin{array}{l}2,00 т ; \\
1,00 ; 3,00\end{array}$ & $\begin{array}{l}1,00 ; \\
0,00 ; 5,00\end{array}$ \\
\hline $\begin{array}{l}\text { Autogenous norm deviation, } \\
\text { standard unit }\end{array}$ & $\begin{array}{l}\text { 12,00; } \\
10,00 ; 16,00\end{array}$ & $\begin{array}{l}16,00 * ; \\
12,00 ; 16,00\end{array}$ & $\begin{array}{l}14,00 * * \\
8,00 ; 16,00\end{array}$ \\
\hline Eccentricity, standard unit & $\begin{array}{l}\text { 10,00; } \\
8,00 ; 11,00\end{array}$ & $\begin{array}{l}\text { 8,00т; } \\
6,00 ; 9,00\end{array}$ & $\begin{array}{l}11,00 ; \\
8,00 ; 12,00\end{array}$ \\
\hline Concentricity, standard unit & $\begin{array}{l}9,00 ; \\
8,00 ; 10,00\end{array}$ & $\begin{array}{l}8,50 ; \\
6,00 ; 10,00\end{array}$ & $\begin{array}{l}5,50 * * * \\
4,00 ; 9,00\end{array}$ \\
\hline $\begin{array}{l}\text { Vegetative coefficient, standard } \\
\text { unit }\end{array}$ & $\begin{array}{l}13,00 ; \\
10,00 ; 16,00\end{array}$ & $\begin{array}{l}15,00 ; \\
13,00 ; 19,00\end{array}$ & $\begin{array}{l}16,00 ; \\
12,00 ; 26,00\end{array}$ \\
\hline Heteronomy, m & $\begin{array}{l}7,00 ; \\
7,00 ; 10,00\end{array}$ & $\begin{array}{l}6,00 * ; \\
4,00 ; 7,00\end{array}$ & $\begin{array}{l}7,00 * \\
6,00 ; 8,00\end{array}$ \\
\hline Autonomy, standard unit & $\begin{array}{l}\text { 10,00; } \\
9,00 ; 11,00\end{array}$ & $\begin{array}{l}11,00 * \\
9,00 ; 12,00\end{array}$ & $\begin{array}{l}10,50 ; \\
9,00 ; 12,00\end{array}$ \\
\hline \multicolumn{4}{|l|}{ Stress test } \\
\hline $\begin{array}{l}\text { Stress tolerance, } \\
\text { standard unit }\end{array}$ & $\begin{array}{l}95,09 ; \\
86,47 ; 114,94\end{array}$ & $\begin{array}{l}94,38 ; \\
88,28 ; 104,12\end{array}$ & $\begin{array}{l}\text { 91,87*; } \\
81,98 ; 102,11\end{array}$ \\
\hline Capacity, standard unit & $\begin{array}{l}1,09 ; \\
0,95 ; 1,23\end{array}$ & $\begin{array}{l}1,15 ; \\
1,08 ; 1,23\end{array}$ & $\begin{array}{l}1,28 * * * ; \\
1,19 ; 1,40\end{array}$ \\
\hline Abando, standard unit & $\begin{array}{l}(-0,07) \\
(-0,11) ;(-0,03)\end{array}$ & $\begin{array}{l}(-0,04)^{*} \\
(-0,09) ;(-0,03)\end{array}$ & $\begin{array}{l}(-0,06) ; \\
(-0,10) ;(-0,03)\end{array}$ \\
\hline
\end{tabular}

Notes: * ${ }^{*} p<0.05$, in comparison with athletes with a high level of motivation to achieve success; $*^{*}-\mathrm{p}<0.05$, in comparison with athletes with an average and above average levels of motivation to achieve success 
success, significantly higher values of neurodynamic parameters are revealed: endurance and stability of the nervous system; balance of nervous processes; throughput of the visual analyzer. In judo athletes with the predominance of motivation to avoid failure, significant differences are revealed by some neurodynamic indicators: the frequency of touching; duty cycle in tapping test conditions; accuracy of the balance of nervous processes. This circumstance indicates a special coping strategy in conditions of psycho-emotional tension in judo [18].

In athletes with high level of motivation to achieve success, prevail the following values of cognitive functions: accuracy and effectiveness of verbal perception. In judo athletes with an average level of motivation to achieve success, the accuracy and effectiveness of nonverbal perception is significantly higher compared to a group of athletes of high level of achievement motivation.

Athletes with an average level of motivation to achieve success identified higher values: productivity; speed, accuracy and effectiveness of verbal information. Athletes with a predominance of motivation to avoid a failure have preference for other groups in the speed, efficiency and stability of the processes of thinking and processing information.

Thus, the thesis about the optimality of motivation of the failure avoidance (the coping strategy) is partially confirmed. Such strategy makes it possible to minimize exhaustion of vegetative resources in conditions of extreme sports activity $[19,20]$.

The mental state of judo has its own characteristics. Mental efficiency is significantly higher in the group of athletes with a predominance of motivation to achieve success in comparison with a group of judo athletes of average level of motivation. It is revealed that in this group of judo athletes the state of relative comfort is associated with the search for support among others and orientation toward internal beliefs [21].

Athletes with average levels of motivation to achieve success and avoid a failure are significantly lower than the indicator of overall mental performance and discomfort in comparison with other groups.
Athletes with high level of motivation to achieve success revealed high stress resistance. The speed of response to stress factors is greatest in a group of athletes with a motivation to avoid failure. The impulsiveness index (not preparedness of actions and the assumption of errors) is significantly higher in the group of athletes with an average level of motivation.

The result is consistent with the early studies. It was found that achieving a certain level of stress resistance is achieved due to the tension of vegetative regulation [22].

\section{Conclusions}

1. High level of motivation to achieve success in judo athletes of high qualification is provided by activation of neurodynamic, cognitive functions and level of light resistance.

2. Judo athletes with predominance of motivation to avoid a failure form a coping strategy to prevent psycho-emotional stress. Such strategy helps to minimize the exhaustion of vegetative resources in conditions of extreme sports activity.

3. The presence of mental state relatively to comfort in judo athletes of high level of motivation to achieve success involves the search for support among others and orientation toward internal beliefs.

4. Judo athletes with high level of motivation to achieve success revealed increased stress resistance. In the group of athletes with the presence of motivation to avoid failure established the best response to stress factors.

\section{Acknowledgments}

The research was carried out in accordance with the Summary Plan of Research and Development in the field of physical culture and sports for 2011-2015, topic 2.23 "Preventive programs of neuropsychophysiological support for athletes of high qualification at the final stages of long-term preparation" (state registration number 0111U001730).

\section{Conflict of interest.}

The authors state that there is no conflict of interest.

\section{References}

1. Balaguer I, Castillo I, Duda JL. Apoyo a la autonomía, satisfacción de las necesidades, motivación y bienestar en deportistas de competición: un análisis de la teoría de la autodeterminación. Revista de Psicología del Deporte. 2008; 17(1): 23-139.

2. Iermakov S, Podrigalo L, Romanenko V, Tropin Y, Boychenko N, Rovnaya O, Kamaev O. Psycho-physiological features of sportsmen in impact and throwing martial arts. Journal of Physical Education and Sport. 2016; 16(2): 433 - 441.

3. Korobeynikov G, Korobeynikova L, Mazmanian K, Jagello W. Diagnostics of psychophysiological states and motivation in elite athletes. Bratislava Medical Journal. 2011; 112(11): 637-643.

4. Teplov BM. Psychology and psychophysiology of personal differences. 2003. (in Russian)

5. Korobeynikov G, Pristupa E, Korobeynikova L, Briskin U. Evaluation of physiological conditions in sport. 2013. (in Ukrainian).

6. Merlin VS. Psychology of personality: selected works. 2005. (in Russian)

7. Ozerov VP. Psychomotor abilities of human. 2002. (in Russian)

8. Duda JL. Motivation in sport. A handbook of competence and motivation. The Guilford Press; 2005.

9. Salamone JD. Motor function and motivation. Encyclopedia of behavioral neuroscience. 2010; 3: 267-276.

10.Korobeynikov G, Korobeinikova L, Latishev S, Shackih V. The impact of emotions on visual-movement performance and effectiveness of competitive activity of elite wrestlers. Applicable Research in Wrestling. 2017;1: 123-128. 
11.Kerr JH. Motivation and emotion in sport: reversal theory. Hove (U.K.): The Psychology Press (Taylor \& Francis); 2013.

12.Kozina Z, Iermakov S, Creiu M, Kadutskaya L, Sobyanin F. Physiological and subjective indicators of reaction to physical load of female basketball players with different game roles. Journal of Physical Education and Sport. 2017; 17: 378-382.

13.Arziutov G, Iermakov S, Bartik P, Nosko M, Cynarski WJ. The use of didactic laws in the teaching of the physical elements involved in judo techniques. Ido Movement for Culture. Journal of Martial Arts Anthropology. 2016; 16(4): 21-30.

14.Korobeynikov G, Korobeinikova L, Shatskih V. Psychophysiological Diagnostics of the Functional States in Wrestlers. International Journal of Wrestling Science. 2013;3(2): 5-13.

15.Mehrabian A. Male and female scales of the tendency to achieve. Educational and Psychological Measurement. 1968; 28 (2): 493-502.

16.Shapkin SA. Questionnaire of achievement motivation: a new modification. Psychologicheskiy jurnal. 2000; 2:113127. (in Russian)
17.Domuschieva-Rogleva G. Determinant of sport motivation with wrestling athletes. Research in Kinesiology. 2015; 43(1): 94-98.

18.Ziv G, Ronnie L. Psychological preparation of competitive judokas. A Review. Journal of sports science \& medicine. 2013; 12(3): 371-377.

19.Korobeynikov G, Korobeinikova L, Mytskan B, Chernozub A, Cynarski WJ. Information processing and emotional response in elite athletes. Ido Movement for Culture. Journal of Martial Arts Anthropology. 2017; 17(2): 21-51.

20.Dalwinder S, Saini S. Sports achievement motivation among wrestlers and judokas-a comparative study. International Journal of Behavioural Social and Movement Sciences. 2013; 2(1): 70-75

21.Filaire E. Psychophysiological stress in judo athletes during competitions. Journal of Sports Medicine and Physical Fitness. 2001; 41(2):263-269.

22.Korobeynikov G, Korobeinikova L, Shatskih V. Age, psychoemotional states and stress resistance in elite wrestlers. International Journal of Wrestling Science. 2013; 3 (1): 5870 .

\section{Information about the authors:}

Korobeynikov G.V.; http://orcid.org/0000-0002-1097-4787; k.george.65.w@gmail.com; National University of Physical Education and Sport of Ukraine; Fizkulture str. 1, Kiev, 03680, Ukraine.

Korobeynikova L.G.; http://orcid.org/0000-0001-8648-316X; korlesia.66@gmail.com; National University of Physical Education and Sport of Ukraine; Fizkulture str. 1, Kiev, 03680, Ukraine.

Romanyuk L.V.; http://orcid.org/0000-0003-0422-1073; Iydmila.romanyuk@icloud.com; Lviv State University of Internal Affairs; Krivonosa St., 1, Lviv, Ukraine.

Dakal N.A.; http://orcid.org/0000-0002-7030-5112; dakalnata@gmail.com; National technical university of Ukraine "Igor Sikorsky Kyiv Polytechnic Institute"; 37, Prosp. Peremohy, Kiev, 03056, Ukraine,

Danko G.V.; http:// orcid.org/0000-0001-9573-6181; k.george.65.w@gmail.com; National University of Physical Education and Sport of Ukraine; Fizkulture str. 1, Kiev, 03680, Ukraine.

Cite this article as: Korobeynikov GV, Korobeynikova LG, Romanyuk LV, Dakal NA, Danko GV. Relationship of psychophysiological characteristics with different levels of motivation in judo athletes of high qualification. Pedagogics, psychology, medical-biological problems of physical training and sports, 2017;21(6):272-278. doi:10.15561/18189172.2017.0603

The electronic version of this article is the complete one and can be found online at: http://www.sportpedagogy.org.ua/index.php/PPS/issue/archive

This is an Open Access article distributed under the terms of the Creative Commons Attribution License, which permits unrestricted use, distribution, and reproduction in any medium, provided the original work is properly cited (http://creativecommons.org/licenses/by/4.0/deed.en).

Received: 15.06 .2017

Accepted: 05.07.2017; Published: 05.11.2017 